\title{
A interferência negativa da discalculia na motivação para a aprendizagem: como melhorar?
}

\author{
Francisco Ronald Feitosa Moraes ${ }^{1}$; Francisco de Carvalho Rodrigues ${ }^{2}$; \\ Marlene Menezes de Souza Teixeira ${ }^{3}$; Gislene Farias de Oliveira ${ }^{4}$
}

\begin{abstract}
Resumo: Dentre as mais variadas causas dificultadoras da aprendizagem da matemática, encontra-se a discalculia. Trata-se de um distúrbio neurológico específico de aprendizagem, decorrente da carência de recursos biológicos relacionados a maturação de certas estruturas cerebrais, que acomete as habilidades cognitivas relacionadas a processos ou tarefas que necessitem do manejo de cálculos, ou conceitos de matemática. Este estudo discute sobre o tema, numa perspectiva de trazer elementos que ajudem no seu mais breve reconhecimento, pelos atores escolares. Dessa forma e, trabalhando de maneira mais focada e específica, pode-se utilizar de uma metodologia mais adequada às necessidades do estudante com tais características. O objetivo final é superar ou amenizar os obstáculos de aprendizado causados pela discalculia.
\end{abstract}

Palavras-chave: Discalculia, Dificuldade de aprendizagem, Matemática.

\section{The negative interference of dyscalculia in motivation for learning: how to improve?}

\begin{abstract}
Among the most difficult causes of learning mathematics is dyscalculia. It is a learning-specific neurological disorder due to the lack of biological resources related to the maturation of certain brain structures, which affects the cognitive abilities related to processes or tasks that require the handling of calculations or mathematical concepts. This study discusses the theme, with a view to bringing elements that help in the briefest recognition, by the school actors. Thus, by working in a more focused and specific way, one can use a methodology more appropriate to the needs of the student with such characteristics. The ultimate goal is to overcome or ameliorate the learning obstacles caused by dyscalculia.
\end{abstract}

Keywords: Dyscalculia, Difficulty in learning, Mathematics.

\footnotetext{
${ }^{1}$ Licenciado em Matemática pela Universidade Regional do Cariri (URCA). Mestre em Educação pela Universidade Federal do Ceará (UFC), Especialista em Psicologia aplicada à Educação (URCA), Metodologia do Ensino de Matemática e Física (UCAM) e Gestão Escolar e Práticas Pedagógicas (UCAM). Professor Temporário de Educação Matemática e Estatística do Curso de Matemática da URCA/Campos Sales. Contato: ronaldmoraes@ymail.com;

${ }^{2}$ Programa de Mestrado em Ciências da Educação pela Anne Sullivan University. Contato:Franciscocrbio@ hotmail.com;

${ }^{3}$ Graduação em Enfermagem pela Universidade Estadual do Ceará; Especialização em Saúde da Família pela Faculdade de Medicina do Juazeiro do Norte; Especialização em Docência do Ensino Superior pela Faculdade Leão Sampaio; Especialização em Enfermagem do Trabalho pela Universidade Vale do Acaraú; Doutorado em Educação em Ciências: química da vida e saúde pela Universidade Federal do Rio Grande do Sul; Atualmente é professora do Centro Universitário Dr. Leão Sampaio; Membro efetivo da Universidade Regional do Cariri. Contato: marlamteixeira@ yahoo.com.br;

${ }^{4}$ Psicóloga, doutorado em Psicologia social e Pós doutorado em Ciências da Saúde. Professora da faculdade de medicina da Universidade Federal do Cariri. Contato: gislene.farias@ufca.edu.br.
} 


\section{Introdução}

A escola tem o papel fundamental de orientar e colaborar para a construção íntima e intelectual dos indivíduos, sendo um dos seus maiores desafios gerir os alunos que apresentam dificuldade para aprender. Sendo assim, alunos com baixa ou nenhuma motivação para aprender e com dificuldades de aprendizagem, tratam-se de um verdadeiro desafio, tendo em vista que os educadores precisam desenvolver uma forma de intervenção diferente e adequada para ensinar conteúdos para esses estudantes.

Dentre as mais variadas causas dificultadoras da aprendizagem, encontra-se a discalculia, que está relacionada ao estudo da matemática. A discalculia é um distúrbio neurológico específico de aprendizagem, decorrente da carência de recursos biológicos relacionados a maturação de certas estruturas cerebrais, que acomete as habilidades cognitivas relacionadas a processos ou tarefas que necessitem do manejo de cálculos ou conceitos de matemática. A enfermidade pode ser verificada nos primeiros anos escolares da criança, isto porque os sintomas são explícitos e perceptíveis nos bloqueios apresentados pelos alunos em relação a assimilação e prática das atividades que envolvam cálculos ou conceitos aritméticos.

Nesse sentido, conforme atestam dados disponibilizados pelo Sistema de Avaliação da Educação Básica (SAEB) e pela Organização das Nações Unidas para a Educação, a Ciência e Cultura (UNESCO), é numeroso o contingente de educandos que apresentam dificuldade em assimilar os conceitos e o raciocínio matemático, bem como de aprender a desenvolver cálculos numéricos. (BASTOS, 2006).

O quadro da enfermidade piora quando o educando é acompanhado por um profissional da educação despreparado para gerir esse tipo de enfermidade, isto porque a dificuldade de aprendizagem do conteúdo matemático também pode ser agravada em decorrência da utilização de um método de ensino inadequado. Isto porque um educador despreparado não utilizará práticas contextualizadas que facilitem o desenvolvimento cognitivo do aluno discalcúlico, o que poderá pôr termo a motivação do aluno em aprender. Nesse sentido, é incontroverso que alunos desmotivados tendem a traçar um percurso de fracasso no âmbito acadêmico.

Ademais, tem-se verificado que os alunos portadores do transtorno têm sua autoestima e autoimagem diretamente atingidas, o que o torna um aluno intimidado pelo julgamento dos demais colegas, bem como dos professores, que teme realizar perguntas para dirimir suas 
dúvidas por ter vergonha que os outros tenham conhecimento de seu nível na matemática, o que constitui um entrave ao aprendizado e também o leva ao insucesso escolar.

Dessa forma, é preciso que o educador detenha de "know how" suficiente que o possibilite identificar os alunos portadores da deficiência e o melhor método educacional a ser aplicado em cada caso. Ademais, laboratórios de aprendizagem têm sido apontados como um ótimo método a ser utilizado com alunos portadores da enfermidade. Nessa perspectiva, com o uso de técnicas adequadas, será possível vencer o óbice ao aprendizado ocasionado pela discalculia por meio do uso de diferentes estratégias complementares ao ensino da matemática, com o escopo de possibilitar ao aluno o desenvolvimento de todas as dimensões da aprendizagem.

\section{Explicando a discalculia}

Conforme ensina a medicina e de acordo com a International Statistical Classification of Diseases, Injuries and Causes of Death, de autoria da Organização Mundial da Saúde, a discalculia consiste em transtorno específico do desenvolvimento das habilidades escolares em aritmética, catalogado no CID-10 MC (2010). No mesmo sentido a Associação Norte Americana de Psiquiatria entendeu, classificando a enfermidade como transtorno relacionado ao desenvolvimento dos neurônios especificamente conectado ao prejuízo do entendimento dos conceitos e cálculos da matemática, fichado no DSM- 5 (2014).

A discalculia trata-se de desordem neurológica que interfere negativamente na aprendizagem do indivíduo de aprender, compreender e manipular conceitos matemáticos e operações numéricas. Nesse sentido, os educandos portadores dessa enfermidade, apresentam dificuldade em entender conceitos, bem como de desenvolver uma cognição intuitiva envolvendo números e operações matemáticas.

(...) discalculia significa, etimologicamente, alteração da capacidade de cálculo e, em um sentido mais amplo, as alterações observáveis no manejo dos números: cálculo mental, leitura dos números e escrita dos números. (VIEIRA, 2004, p. 11).

Estudos neuropsicológicos acerca da temática, revelam que a discalculia decorre do desenvolvimento insuficiente do campo cerebral responsável pelas funções neuropsicológicas 
relacionadas aos processos de realização de contas matemáticas. Assim, os alunos portadores desse transtorno dispõem de um transtorno cerebral que interfere em sua capacidade de investigar, compreensão e reconhecer números, o que dificulta diretamente sua habilidade de realizar operações numéricas fundamentais, cálculos mentais ou expressões numéricas simples. (CHRISTENSEN, 1987, p. 202).

O termo foi apresentado pela primeira vez pelo psicólogo Ladislav Kosc (1974), que realizou os primeiros estudos relacionados com a discalculia. Para Kosc, a enfermidade consiste desordem congênita que acomete substrato anatômico-fisiológico relacionado com a maturação das capacidades numéricas, o que ocasiona um desarranjo total nas habilidades matemáticas do educando. Outrossim, a discalculia não envolve lesões cerebrais, sendo causada por deficiência na maturação do sistema neurológico relacionado com as capacidades matemáticas, não sendo, dessa forma, algo que acomete o estudante de forma generalizada.

Com base nisso e com vistas a possibilidade da enfermidade poder se apresentar combinada com outras doenças ou transtornos de aprendizado, o psicólogo Ladislav Kosc elaborou uma classificação na qual apresentou seis subtipos de discalculia, sendo elas: (i) verbal, em que o indivíduo apresenta dificuldade identificar quantidades, números, termos matemáticos; (ii) practognóstica, relacionada com problemas de enumeração, comparação e manipulação de objetos ou imagens; (iii) léxica, na qual o estudante apresenta bloqueios para a leitura de símbolos da matemática; (iv) gráfica, relacionada aos problemas de escrever os símbolos matemáticos; (v) ideognóstica, marcada pelo embaraço na realização de cálculos matemáticos mentais e da dificuldade em compreender os conceitos básicos da matemática; e (vi) operacional, que está relacionada a dificuldade do aluno em fazer operações com números e cálculos matemáticos.

Ainda, tomando por base a causalidade, pode-se classificar a discalculia em: (i) adquirida, quando decorre de herança sócio-histórico-cultural, ou seja, causada por fatores ambientais que causam alterações no cérebro do educando que anteriormente possuía bom desempenho; e (ii) do desenvolvimento, que está relacionada aos componentes genéticos da criança. (BUTTERWORTH; VARMA; LAURILLARD, 2011, p. 1049).

A discalculia apresenta uma característica específica que a diferencia da dificuldade de aprendizagem, que é representada pela dificuldade crônica de processar e entender, especificamente, os números e cálculos matemáticos, que não decorre da complexidade do conteúdo ministrado em sala de aula, da forma de ensino, tampouco da falta de motivação do 
estudante. $\mathrm{Na}$ verdade, decorre de fatores mais intrínsecos e que possui forte relação com a dislexia (HAASE, 2011).

A doença pode ocorrer em razão de imaturidade, em diferentes graus de intensidade, das funções neurológicas, que interferem no processo evolutivo intelectual do indivíduo; podendo, da mesma forma, se apresentar em alunos aparentemente saudáveis e com grande potencial de inteligência nas outras áreas de ensino, isto porque consiste em problema relacionado com a dificuldade de entender e realizar cálculos matemáticos, podendo o indivíduo possuir cognição suficiente em relação às demais disciplinas de ensino escolar.

Inclusive, desde a pré-escola os sintomas da discalculia podem ser identificados, onde o aluno apresenta dificuldade de aprender os conceitos matemáticos básicos, bem como a noção de quantidades, de mais e menos, pouco e muito, antes e depois, noções de tempo e espaço. Da mesma forma, pode ser verificada em dificuldades de raciocínio e pensamento abstrato, quando o educando comete diversos erros nas atividades de matemática, alertando seu problema em compreender os números, de contar e solucionar problemas.

De acordo com o DSM-5 (2014), existem quatro formas de identificar a presença do transtorno: (i) quando o aluno apresenta dificuldade de aprender e utilizar as habilidades acadêmicas básicas já nos primeiros anos da escolarização formal, demonstrando problemas para dominar o senso numérico, executar cálculos ou de raciocínio lógico, devendo o sintoma persistir por, no mínimo, 6 meses; (ii) caso as capacidades acadêmicas demonstram-se substancialmente e quantitativamente abaixo da expectativa para a faixa etária do educando, interferindo significativamente no desempenho escolar, profissional ou cotidiano, devendo ser confirmada por meio de avaliação clínica; (iii) quando os problemas de aprendizagem se manifestam com o avanço e aumento de complexidade do conteúdo, momento em que as capacidades intelectuais máximas do estudante serão atingidas; e, por fim, informa no critério (iv) que limitações intelectuais, visual, auditiva, outros transtornos de ordem neurológica ou psicológica, fatores socioculturais, ausência de proficiência na língua ou instrução escolar inadequada, não são suficientes para identificar a presença da discalculia.

Não consistem em difícil tarefa a constatação do aluno que possui discalculia, isto porque logo se percebe sua dificuldade excessiva em relacionar termos; associar os símbolos da adição, subtração, multiplicação e divisão; de contar; de entender os sistemas cardinais e ordinais; realizar operações aritméticas simples; de ordenar números, dentre outros. Sendo detectada, o professor poderá colaborar para a diminuição dos danos causados pela 
enfermidade, pois a percepção da limitação do aluno, permitirá que o educador atue no sentido de ajudá-lo de forma específica.

Dessa forma, é evidente o importante papel do educador no acompanhamento da aprendizagem de seus alunos, para fins de verificar possíveis irregularidades e, assim, atuar ativamente no sentido de tentar contornar ou mitigar os efeitos de possíveis deficiências apresentadas pelos educandos.

\section{Perda de autoestima, mitigação da autoimagem e desmotivação de aprender causados pela discalculia}

O processo de ensino-aprendizagem envolve todas as dimensões do educando, desde a cognitiva até a afetiva e social. Nesse diapasão, é incontroverso que a percepção de ser portador de limitação pelo estudante, interferirá negativamente em sua autoestima e autoimagem, bem pode desmotivá-lo a aprender.

Como é sabido, tanto a autoestima quanto a autoimagem são provenientes de uma composição de sentimentos decorrentes das relações interpessoais e intrapessoais de um indivíduo. Assim, os vínculos interativos que o educando mantém com família, com os amigos e professores na escola e com a sociedade em geral; interferem na dimensão afetiva do estudante de forma particularizada, que não pode ser pré-determinada geneticamente, isto porque a percepção de autoestima e autoimagem será construída de forma individual, a depender da qualidade e quantidade das interações estabelecidas pelo aluno e do meio em que vive.

Desse modo, a autoestima será uma média de uma autoavaliação que a pessoa faz de si mesma com base nas interações que estabelece em seu meio social, gerando uma autocaracterização de si mesma que a diferencia ou assemelha aos demais. Caso essa média seja elevada, a pessoa tende a se valorizar e se sentir bem consigo; sendo abaixo do esperado, tende a não se sentir valorizada, desenvolvendo uma baixa autoestima.

Nesse sentido, os valores desenvolvidos pelo educando, consiste em um produto da assimilação de suas ações no meio em que vive, em que o sucesso ou o fracasso dessas ações determinará o sentimento de superioridade ou inferioridade no íntimo e pessoal do estudante, o que, consequentemente, será o norte de seu autojulgamento e de sua autovalorização ou não (FARIA, 1989, p. 20). Assim, um estudante que tenha experimentado mais sucessos do que 
fracassos durante sua vida estudantil, desenvolve um sentimento de "eu valorizado", o que o motivará a continuar desafiando novas situações e atividades acadêmicas. Da mesma forma ocorre com o aluno discalcúlico, onde o dissabor experimentado pelos recorrentes fracassos com o estudo da matemática, desenvolve em seu íntimo e pessoal sentimentos negativos, o que finda na desmotivação em aprender a matéria.

A autoestima está relacionada com a percepção de autovalorização, crença na própria capacidade, nos conceitos que a pessoa tem de si mesma, dos outros e do mundo em geral. Na verdade, a autoestima pode ser definida como sendo uma situação-ideal em que a pessoa se ama (LORENTE, 2004, p. 21). Inclusive, segundo Maslow (1993), trata-se de necessidade estruturante vital que precisa ser satisfeita para o indivíduo possa ter coragem e motivação de enfrentar demais situações da vida.

Para Maslow, todo indivíduo possui certas necessidades básicas que precisam ser supridas, que variam de níveis e intensidade de pessoa para pessoa. As referidas necessidades podem ser divididas da seguinte forma: (i) fisiológicas, como sede, fome, sono, etc; (ii) securitárias, que envolve a necessidade de proteção; (iii) afetivas, que está relacionada com a necessidade de ter amor e construir laços afetivos, (iv) de ter estima, onde está autoestima e necessidade de ser respeitado, e, por fim, (v) de auto-realização, que envolve o desenvolvimento e aprimoração de suas capacidades e talentos.

Smith e Strick (2001), ao comentarem sobre a classificação das necessidades basilares de Maslow, ressaltam que existe uma hierarquia entre elas, que variará a depender, principalmente, da situação socioeconômica do estudante, isto porque educandos financeiramente fragilizados, vivenciam diversos óbices para satisfazer sua fome, sede e moradia, ou seja, suas necessidades fisiológicas, além de apresentarem dificuldades de suprirem as demais necessidades, o que gera uma criança com autoconfiança mitigada e com dificuldade de enfrentar os desafios da vida, o que é visivelmente diferente do que ocorre com estudantes com vida financeira confortável.

Conforme ensina William James (apud POLAINO LORENTE, 2004), a autoestima pode ser dividida em três subtipos: (i) material, sendo esta relacionada às condições financeiras do indivíduo; (ii) social, que envolve a vida social e familiar da pessoa; e (iii) espiritual, sendo esta aquela relacionada ao sentimento de superioridade ou não.

Com isso, a autoestima consiste em sentimento resultante da composição desses três subtipos, - que levam em conta as potencialidades do indivíduo e a realidade em que ele está 
inserido-, podendo ser equalizada como: autoestima = êxito/pretensões. Nesse sentido, quanto maiores forem as expectativas estabelecidas e não atingidas, menor será a autoestima resultante; e quanto menores as pretensões almejadas e grandes os êxitos obtidos, maior será a autoestima.

Para a psicologia contemporânea, a autoimagem/autoconceito também consiste em objeto de suma importância da vida pessoal, isto porque, a ideia do "eu" como um conhecimento de si mesmo, envolve diversas dimensões da vida do indivíduo, desde sua aparência até sua personalidade e habilidades (MIRAS, 2004, p. 210). Com isso, trata-se de conceito que vai sendo construído e modificado ao longo da vida humana, estando diretamente ligado ao desenvolvimento de uma estima positiva ou não.

Nesse diapasão, no âmbito educacional, os estudantes possuem um tipo de "autoconceito acadêmico" relacionado à noção que possui de si na posição de estudante e aprendiz. Esse autoconceito será diferente a depender da matéria, e envolverá a análise das capacidades e habilidades de aprender do discente. Nesse sentido, no momento em que o estudante tem seu "autoconceito acadêmico" debilitado em relação à matemática, ele se torna um aluno desinteressado e inseguro em realizar as tarefas que lhe forem postas, isto porque este será um momento em que o educando se verá emocionalmente ameaçado e carregado de desânimo por prever um novo fracasso, que lesará ainda mais sua autoestima.

O desenvolvimento da autoestima envolve os sentimentos de capacidade e autoconfiança, que estão intimamente ligados às experiências de vida. No caso específico do aluno discalcúlico, seus insucessos relacionados a prática da matemática prejudicam a construção de sua autoestima, o que, consequentemente, prejudica a sua auto-imagem, pois a autoimagem depende do desenvolvimento do indivíduo em contato com o meio em que vive, principalmente das relações sociais.

A auto-imagem consiste em manifestação do íntimo e pessoal do indivíduo, que reflete suas relações pessoais e laços socioafetivos com pais, amigos, educadores e com a sociedade como um todo; em que a partir da percepção do que os outros têm dele, o aluno constitui sua auto-imagem. Com isso, é notório que os aspectos emocionais têm o condão de interferir diretamente na autoestima e autoimagem do aluno. Nesse sentido Smith e Strick (2001, p. 76) comentam:

"Os alunos com baixo desempenham escolar a longo prazo tendem a ver a si mesmos como
incapazes de aprender; eles antecipam o fracasso e são bem menos persistentes do que os alunos 
que acreditam na existência de uma relação entre o trabalho duro e o sucesso [...] assim, a crença na própria capacidade para ter sucesso é essencial para qualquer espécie de conquista”.

A presença de uma auto-estima fragilizada torna o estudante mais sensível aos julgamentos negativos e carregados de desprestígio dos outros estudantes e educadores, além de desenvolver sentimentos negativos de inferioridade, falta de merecimento e insegurança, que podem o transformar em um aluno ansioso, depressivo e ineficaz; podendo, ainda causar uma falta de autoconsciência no estudante, que poderá apresentar temperamentos agressivos e destrutivos (MURK, 1998). (ok)

No âmbito escolar, o medo do julgamento negativos dos demais constitui um óbice ao aprendizado de qualquer estudante, em especial dos portadores de deficiências de aprendizagem, isto porque este se sentirá inibido de perguntar algo ou participar da aula, para não revelar seu real nível de conhecimentos. O medo do fracasso faz com que a atividade de aprendizagem se torne um verdadeiro tormento, já que o aluno não conseguirá acompanhar o conteúdo ministrado, o que se tornará pior a cada aula, visto que a tendência é que os conteúdos sejam mais complicados com o avançar da matéria.

Conclui-se, dessa forma, que uma autoestima e autoimagem prejudicada tem a capacidade de interferir negativamente no desenvolvimento e a aprendizagem do educando, isto porque o êxito educacional do aluno depende em grande parte da confiança que o estudante tem em seu potencial enquanto aluno e aprendiz.

\section{Laboratórios de aprendizagem: uma possível solução}

Sem dúvidas todos estudantes, sejam eles deficientes ou não, com dificuldades reais, circunstanciais, fisiológicas, psicológicas, cognitivas ou sociais, possuem direito de serem aceitos e respeitados, cada um em seu tempo particular de aprendizado. (MANTOAN, 2004, p. 33). Assim, havendo estudantes que apresentem dificuldades de aprendizado, seja em decorrência de enfermidade constatada ou não, é necessário que a escola elabore um método educacional complementar, para fins de suprir as necessidades e colaborar no desenvolvimento das potencialidades desses estudantes.

O laboratório de aprendizagem, é local de Atendimento Educacional Especializado (AEE) pioneiro na educação inclusiva, implantado nas escolas públicas de alguns municípios e 
voltado para estudantes com problemas de aprendizagem, mas sem uma síndrome previamente definida. No entanto, até 2011, também eram utilizadas para ajudar alunos com deficiências graves de aprendizagem (REIS, 2012, p. 15) e mostrava-se ferramenta útil e eficaz para tanto.

Trata-se de local de pesquisa e ressignificações para os educandos que possuem um ritmo diferenciado dos demais colegas de classe. Não há o intuito de adequar o aluno ao ritmo dos demais, tampouco de curar o estudante; na verdade, busca-se conhecer as limitações do educando (LEONÇO, 2002, p. 54) para fins de utilizar um método de ensino adequado às suas necessidades. Nesses laboratórios, o estudante discalcúlico poderá aprender de forma diferentes e no seu próprio tempo, sendo local de reconstrução de conceitos e espaço de exposição de dúvidas sem medo de possível julgamento negativo.

Para tanto, é preciso que o professor seja suficientemente capacitado para lidar com alunos discalcúlicos, devendo ser paciente e criativo. Algumas características são importantes para um professor participante de laboratórios de aprendizagem, tais como: (i) domínio de todas as etapas do processo de aprendizagem; (ii) conhecer dos diferentes métodos de ensino para alunos com ritmo diferenciado; (iii) ser flexível, sendo aberto a possibilidade de mudança de planejamento caso o aluno ainda não esteja conseguindo acompanhar ou ache as atividades fáceis; e (iv) ser tolerante e demasiadamente tolerante, isto porque haverá a necessidade de repetir conteúdos ou ensinar de diferentes formas, até o aluno aprender (DORNELES, 2004, p. 215).

Isto porque deve ser um local que oportunize o educando de aprender os novos conteúdos escolares, somando aos conhecimentos que o aluno já detenha. Segundo Vygotsky (1991), o laboratório de aprendizagem trabalha a zona de desenvolvimento proximal (ZDP), em que o professor ocupa lugar de suma importância de mediador entre o discente e o mundo do aprendizado.

Ademais, o docente pode utilizar desse recurso para fins de reconstruir conceitos, dirimir dúvidas e realizar pesquisas sobre o processo de aprendizagem e os diferentes métodos que podem ser utilizados a depender do ritmo do educando (LOUREIRO, 2010). Isto porque o professor precisa deter conhecimentos específicos sobre as mais diferentes formas de desenvolvimento do processo de ensino e aprendizagem de alunos discalcúlicos. Conforme comenta Baptista (2011, p.60): 
Estou considerando educador especializado em educação especial ou educador especial aquele com formação específica: curso de graduação na área; em pedagogia, com habilitação específica; curso de especialização ou estudos complementares. Essa pluralidade de dimensões quanto à formação é garantida pela legislação atual, a qual não define especificamente uma trajetória.

O laboratório de aprendizagem deve ser um ambiente de acolhimento e superação a ser utilizado por alunos que não se adequam ao sistema usual de ensino e aprendizagem. Nesse meio, serão possibilitados aos estudantes meios alternativos de superação de suas dificuldades e desenvolvimento das capacidades, com o escopo de ajudá-lo a melhorar sua autoestima e autoimagem.

\section{Outras técnicas pedagógicas a serem aplicadas aos alunos discalcúlicos:}

Os parentes necessitam buscar conhecer da doença para fins de compreender e aprender a interagir com a criança, bem como é preciso alertar as demais pessoa do convívio sobre a presença do transtorno, como forma de prevenir possíveis prejuízos ao desenvolvimento do aluno.

Primordialmente, urge salientar que a enfermidade não impede o processo de aprendizagem, apenas carece de uma forma diferenciada de não convencional de ensino. Assim, é preciso o desenvolvimento de métodos, técnicas de ensino e atividades escolares diferenciadas, com uso de recursos didáticos adaptados ao nível e ritmo de aprendizado do educando. (VIGNOLA, 2015; SANTOS; SILVA; RIBEIRO et al., 2010, p. 28-29).

O método de ensino utilizado com os alunos portadores do transtorno deve , primeiramente, analisar o nível de compreensão da matemática pelo estudante e identificar os equívocos causados pela criança. Com isso, será possível definir um projeto de aula específico e personalizado para as necessidades do educando, por meio de um sistema cumulativo e multisensorial.

Além disso, alguns autores (BERNARDI, 2014, p. 71-88; CAMPOS, 2014, p. 53-61; BELLOS, 2011; KAUFMANN, 2008, p. 163-175) indicam estratégias a serem utilizadas como forma de mitigar os déficits executivos, bem como diminuir o impacto negativo da escola no estudante, buscando como resultado a melhora das habilidades intelectuais e acadêmicas do portador da enfermidade. 
As referidas táticas de ensino devem permitir que o educando utilize inicialmente os dedos para a realização das contas, uma vez que trata-se de fase importante no aprendizado da matemática; permitir a realização de rascunhos e uso de calculadora; associar o assunto ministrado à imagens, tais como tabelas e diagramas, que ilustrem os conceitos ensinados; encorajar o aluno a realizar a representação matemática dos conceitos com uso de desenhos para representar o cálculo. Ademais, indicam que o uso de rimas, dicas e macetes, consiste em algo que colabora para o aprendizado, principalmente quando associado a cartões de lembretes. Ainda, é interessante utilizar mnemônicos, que podem ser associados a ritmos e música, para ajudar na memorização do conteúdo.

Além disso, é importante iniciar o estudo com pequenos números e gradualmente passar a utilizar números maiores; introduzir o vocabulário específico da matéria a ser lecionada antes de iniciar a aula propriamente dita; e ensinar o estudante a identificar padrões numéricos, mesmo que isso seja uma tarefa árdua, para que a criança possa relacionar fatos diferentes ao que foi aprendido. Incentivar o discente a explicar o que foi aprendido também consiste em método eficaz ,bem como o uso de situações cotidianas, como compras na padaria, para que os números e cálculos passem a fazer sentido para o estudante por meio da associação do conteúdos as situações do dia-a-dia.

Por fim, os autores também alertam acerca da importância priorizar a qualidade dos conteúdos e tarefas ministradas, e não a quantidade de tarefa posta, sendo interessante dividir as atividade em proporções menores, para facilitar a assimilação do conteúdo da vez. Nesse diapasão, o uso de jogos, como sudoku, e demais brincadeiras, como dominó e pular amarelinha, também são importantes subterfúgios no ensino da matemática para alunos discalcúlicos.

Conforme pode-se verificar, tratam-se de estratégias que buscam facilitar o ensino e aprendizado da matemática pelos alunos portadores da discalculia por meio do uso de métodos diferenciados e inovadores, que parecem básicos, mas têm se revelado como alternativa útil e eficaz de ensino da matéria ministrada através do uso de novos métodos, técnicas e espaços. 


\section{Considerações Finais}

O presente estudo teve por objetivo analisar as dificuldades específicas no estudo das ciências matemáticas, em especial a discalculia, que consiste em distúrbio neurológico que atinge grande quantitativo de jovens estudantes, razão pela qual se torna importante investigar essa enfermidade, bem como os métodos pedagógicos voltados para a educação especial, com o escopo de encontrar uma forma alternativa de contornar essa problemática.

No palco educativo, a discalculia além dar causa a dificuldade de aprendizado do aluno, tem como consequência a mitigação da autoestima e autoimagem do estudante, uma vez que o estudante passa a se sentir diminuído em relação aos demais colegas, assim como envergonhado de revelar sua dificuldade de assimilar o conteúdo matemático.

A autoestima e a autoimagem consistem em uma avaliação e autoconceito que a pessoa constrói de si, estão ligados a valorização pessoal. Sem dúvidas, ambas são relevantes na vida do estudante para sua interação com o mundo, razão pela qual a criança com discalculia também deve ter trabalhado o seu caráter afetivo e emocional no processo ensino aprendizado.

Frente a existência de enfermidade que acomete a sagacidade do aprendizado dos estudante em matéria escolar importante para a vida como um todo, qual seja a matemática, podendo, ainda, ter repercussão negativa na seara afetiva; é de grande valia que a escola possua um sistema qualificado de educação alternativa voltado para tais estudantes que fogem ao padrão convencional de aprendizado.

Nesse diapasão, os laboratórios de aprendizagem têm se apresentado como estratagema eficaz para a educação especializada, onde o estudante é incentivado e desafiado a aprender de formas alternativas, com fulcro de estimular sua autonomia no desenvolvimento da busca e aquisição do aprendizado, sendo, dessa forma, instrumento de grande valia para as instituições escolares.

Indubitavelmente, a escola deve ser ambiente capaz de gerir as necessidades específicas de seus alunos, promovendo o desenvolvimento intelectual de todos, com o objetivo de encaminhar os educandos para o sucesso e desenvolvimento de suas competências. Assim, aponta-se a necessidade de existência de método sistemático pedagógico mais equitativo, que busque a inclusão educacional dos alunos discalcúlicos, respeitando suas diversidades e 
características particulares, sempre buscando o estímulo das potencialidades matemáticas dos estudantes.

Diante do exposto, é de suma importância que todos os atores da instituição escolar saibam reconhecer os sintomas da enfermidade, para que possam trabalhar de forma específica e direcionada o distúrbio do discente, com o uso de métodos diversificados e adequados à necessidade do estudante, com o objetivo final de superar ou amenizar os obstáculos de aprendizado causados pela discalculia.

\section{Referências}

BASTOS, J. A. Transtornos da aprendizagem. In: R, N.; O, L.; R, R. Transtornos da aprendizagem: Abordagem neurobiológica e multidisciplinar. Porto Alegre: Artmedas, 2006.

BELLOS, Alex. Alex no país dos números. São Paulo: Companhia das Letras, 2011. Disponível em: <https://www.companhiadasletras.com.br/trechos/12579.pdf>. Acesso em: 01/07/2018.

BERNARDI, J. Alunos com discalculia: o resgate da autoestima e da autoimagem através do lúdico. Dissertação (Mestrado em Educação). Porto Alegre, Pontifícia Universidade Católica do Rio Grande do Sul. 2006. Disponível em: <http://repositorio.pucrs.br/dspace/bitstream/10923/2901/1/000386384-Texto\%2bCompleto0.pdf $>$. Acesso em 30/06/2018.

BERNARDI, J. STOBAUS, C. D. Discalculia: conhecer para incluir. Rev. Educ. Espec., Santa Maria, v. 24, n. 39, p. 47-60, jan./abr. 2011. Disponível em: $<$ https://periodicos.ufsm.br/educacaoespecial/article/view/2386/1715>. Acesso em $30 / 06 / 2018$.

BERNARDI, Jussara. Discalculia: o que é? Como intervir? Jundiaí, SP: Paco, 2014.

BUTTERWORTH, Brian; VARMA, S.; LAURILLARD, D. Dyscalculia: from brain to education. Science, v.332, p. 1049-1053, maio 2011. Disponível em: <http://www.sciencemag.org/> . Acesso em: 01/07/2018.

CAMPOS, Ana Maria Antunes de. Discalculia: superando as dificuldades em aprender matemática. São Paulo: WAK, 2014.

CHRISTENSEN, A. El diagnóstico neuropsicológico de Luria. 2. ed. revisada. Madrid: Visor, 1987. $202 \mathrm{p}$. 
CONSENZA, R. M.; GUERRA, L. B. Neurociência e educação: como o cérebro aprende. Porto Alegre: Artmed, 2011

CID-10 MC. Classificação Internacional de Doenças e problemas relacionados à Saúde. 10. ed. Organização Mundial da Saúde. 2010. Disponível em: <http://www.datasus.gov.br/cid10/V2008/WebHelp/f80_f89.htm> . Acesso em: 01/07/2018.

CURVO, E. F. Discalculia: autoimagem e autoestima. 2018. Disponível em: $<$ https://www.webartigos.com/artigos/discalculia-autoimagem-eautoestima/157762\#ixzz5Jph55k8Dhttps://www.webartigos.com/artigos/discalculiaautoimagem-e-autoestima/157762\#ixzz5Jph55k8D>. Acesso em 30/06/2018.

DORNELES, B. V. As várias faces do caleidoscópio: anotações sobre o fracasso escolar. Pátio da Revista Pedagógica. Porto Alegre: Artmed, p. 212-224, set/2004.

DSM-5. Manual Diagnóstico e Estatístico de Transtornos Mentais. Associação Psiquiátrica Americana. 5. ed. Porto Alegre: Artmed, 2014. Disponível em: <https://blogs.sapo.pt/cloud/file/b37dfc58aad8cd477904b9bb2ba8a75b/obaudoeducador/2015 /DSM\%20V.pdf> . Acesso em: 01/07/2018.

FARIA, A. R. de. Desenvolvimento da criança e do adolescente segundo Piaget. São Paulo: Ática, 1989.

HASSE, V. G.; FERREIRA, F. O. Neurociência cognitiva e educação matemática. In: IV Encontro de Educação Matemática de Ouro Preto, 2010. Anais eletrônicos. Disponível em http://www.researchgate.net/publication/216808626_Neurociência_cognitiva_e_educação_ma temática. Acesso em: 01/07/2018.

KAUFMANN, Liane. Dyscalculia: neuroscience and education. Education Research, Windsor, v.50, n.2, p.163-175, jun. 2008.

KOSC, L. Developmental dyscalculia. Journal of Learning Disabilities, v. 7, p. 164-177, 1974. Disponível em: <http://journals.sagepub.com/doi/abs/10.1177/002221947400700309> . Acesso em: 01/07/2018.

KRANS, C. R.; HEALY, L. Pesquisas sobre discalculia no Brasil. Uma reflexão a partir da perspectiva histórico-cultural. Rev. Educ. Espec., Santa Maria, v. 24, n. 39, p. 47-60, jan./abr. 2011 Disponível em: <http://www.matematicainclusiva.net.br/pdf/PESQUISAS\%20SOBRE\%20DISCALCULIA\% 20NO\%20BRASIL.pdf>. Acesso em 10/06/2018.

LEONÇO, V. C. Laboratório de Aprendizagem: Espaço de Superação. Revista Ciência e Letras. Porto Alegre: FAPA, no 32, p. 52-55, dez/2002.

LOUREIRO, C. R. N. S. Laboratório de Aprendizagem: uma invenção do/no espaço escolar. UERJ, Rio de Janeiro, 2010. Disponível em: 
$<$ http://33reuniao.anped.org.br/33encontro/app/webroot/files/file/P\%C3\%B4steres\%20em\%2 OPDF/GT12-6787--Int.pdf> . Acesso em 30/06/2018.

PINHEIRO, M.; LIBLIK, A. M. O. Entendendo a discalculia: formando professores para a educação integral. III Congresso Nacional de Educação. 2016. Disponível em: <http://www.editorarealize.com.br/revistas/conedu/trabalhos/TRABALHO_EV056_MD1_SA 4_ID8179_30072016114236.pdf>. Acesso em: 01/07/2018.

MOSQUERA, J. Psicodinâmica do aprender. 3. ed. Porto Alegre: Sulina, 1984.

MOSQUERA, J. A motivação humana na concepção de Abraham H. Maslow. In: MOREIRA, Marco A. et al. Aprendizagem: perspectivas teóricas. Porto Alegre: Editora da Universidade/PADES/UFRGS/PROGRAD, 1985.

MRUK, C. Auto-estima. Investigación, teoría y práctica. Bilbao, Espanha: Desclée de Brouwer, 1998.

POLAINO L. A. Familia y autoestima. Barcelona: Ariel, 2004. Secretaria Municipal de Educação. Cadernos Pedagógicos n. 9: Ciclos de formação - Proposta político-pedagógica da escola cidadã. Porto Alegre: SMED, 1999.

REIS, J. H. V. Laboratório de Aprendizagem: a história e o fazer pedagógico de um espaço de atendimento educacional especializado. Monografia (Curso de Especialização em Educação Especial e Processos Inclusivos). Universidade Federal do Rio Grande do Sul. 2012. Disponível em: <http://www.lume.ufrgs.br/bitstream/handle/10183/69864/000875105.pdf? sequence=1>. Acesso em 30/06/2018.

SMITH, C.; STRICK, L. Dificuldades de aprendizagem de A a Z. Porto Alegre: Artmed, 2001.

STOBAUS, C. D. BERNARDI, J. Discalculia: conhecer para incluir. Revista Educação Especial. 2011;24(39):47-59. Disponível em: <https://doaj.org/article/6ef57a3e99524bd1ab8da2d2fd0de5e8>. Acesso em 10/06/2018.

VIEIRA, E. Transtornos na aprendizagem da matemática: número e discalculia. Revista Ciências e Letras, n. 35, p. 109-119, 2004.

VIGOTSKY, L.S. A formação da mente. São Paulo: Martins Fortes. 1991.

\section{Como citar este artigo (Formato ABNT):}

MORAES, Francisco Ronald Feitosa; RODRIGUES, Francisco de Carvalho; TEIXEIRA, Marlene Menezes de Souza e OLIVEIRA, Gislene Farias de. A interferência negativa da discalculia na motivação para a aprendizagem: como melhorar?. Id on Line Rev.Mult. Psic., 2018, vol.12, n.41, p.961-976. ISSN: 1981-1179.

Recebido: 25/07/2018.

Aceito: 27/07/2018 